diagnostic delay, nocturnal disturbed sleep, shorter sleep latency and greater number of Sleep Onset REM Periods at Multiple Sleep Latency Test. On the other hand, treatment and disease duration, positively influenced the behavioral evolution. The psychosocial health of pediatric $\mathrm{NC}$ also turned out to be worse than in healthy controls, while the physical health showed no significant differences.

Conclusions We found a specific psychopatological profile in a large pediatric NC sample, compared with another neurological chronic disease (epilepsy) and healthy controls. Symptoms of withdrawal, depression and somatic complaints, were specific of NC, and not observed in the two other groups. Effective treatment, and self-awareness of the disease should be promoted in NC children for the positive impact on behaviour and psychosocial health.

\section{SLEEP PROBLEMS AND ADHD. EPIDEMIOLOGICAL STUDY IN SCHOOL CHILDREN IN ANDALUSIA, SPAIN}

doi:10.1136/archdischild-2012-302724.1815

'A Lora-Espinosa, ${ }^{2 M J}$ Díaz-Aguilar, ${ }^{3 R}$ Jiménez-Alés, ${ }^{4} \mathrm{~N}$ Palomino-Urda, ${ }^{3} \mathrm{R}$ HerguetaLendínez, ${ }^{5} \mathrm{M}$ Montes-Peña, ${ }^{6} \mathrm{~J}$ Murcia-García, ${ }^{7} \mathrm{~N}$ Martinez-Moral, ${ }^{7} \mathrm{~J}$ Barea-Garcia, ${ }^{7}$ A Prosper-Gibert. 'Servicio Sanitario Público Andalucia, Unidad Investigacion Distrito Sanitario Malaga; ${ }^{2}$ Centro de Educación del Profesoradp, Málaga; ${ }^{3}$ Servicio Sanitario Público Andalucia, Sevilla; ${ }^{4}$ Servicio Sanitario Público Andalucia, Granada; ${ }^{5}$ Servicio Sanitario Público Andalucia, Córdoba; ${ }^{6}$ Servicio Sanitario Público Andalucia, Jaén; ${ }^{7}$ Servicio Sanitario Público Andalucia, Cadiz, Spain

$\mathrm{ADHD}$ and sleep-problems frequently overlap and their relationship is complex and bidirectional. The association between ADHD and sleep-problems has been little studied in our community.

Objectives To find out the frequency of sleep-problems among ADHD children from 6-14 year old in Andalusia, Spain.

Methods Prevalence study. Target population: school-students $6-14 y=686.332$ children; centres $=2.493$. Multistage cluster sampling centres $=74$

Method Questionnaires-DSM-IV-TR-ADHD and performance Vanderbilt-parents-and-teachers, sleep-questionnaire (BEARS), interview and medical examination.

Results $\mathrm{N}=1963$.

Meet criteria-DSM-IV-R-ADHD=157, male $=111$, female $=46$; $\mathrm{ADHD}-\mathrm{IA}=62, \mathrm{ADHD}-\mathrm{HI}=31, \mathrm{ADHD}-\mathrm{C}=64$; control=197Comorbidity $\mathrm{ADHD}$-sleep-problems: Sleep-problems in the first year of life: $36 \%$ $\mathrm{ADHD}, 25 \%$-control. ( $\mathrm{p}=0.03)$. Bedtime resistance:30\%-ADHD, $6 \%$-control. $(\mathrm{p}=0.000)$. Daytime sleepiness: $10 \%$-ADHD, 1.5\%-control. $(\mathrm{p}=0.000)$. Night- Awakenings:14\%-ADHD, 2\%-control. $(\mathrm{p}=0.000)$. Snoring: $20 \%$-ADHD, 5.6\%-control. $(\mathrm{p}=0.000)$ Sleepwalking and sleep terrors: $14 \%-\mathrm{ADHD}, 2.5 \%$-control. $(\mathrm{p}=0.000)$. Periodic limb movements in sleep: $51 \%-\mathrm{ADHD}, 8 \%$-control. $(\mathrm{p}=0.000)$. Enuresis:18\%-ADHD, $4.6 \%$-control. $(\mathrm{p}=0.000)$ Regular time for bed: only 36\%-ADHD. Bedsharing:18\%-ADHD. $\geq 3$ sleep problems: 36\%-ADHD. 12\%- control. The association between $\mathrm{ADHD}$ subtypes and sleep-problems showed significant differences.

Conclusions The children with ADHD had more sleep-problems that control children.

The relationship between sleep disorders and ADHD should be considered by paediatricians as part of the global approach to the management of $\mathrm{ADHD}$.

\section{SLEEP PATTERN AND SLEEP DISORDERS IN PRESCHOOL- AGED CHILDREN}

doi:10.1136/archdischild-2012-302724.1816

M Taşar, H Boztepe, Ş Yıldırım, Y Dallar Bilge. Pediatrics, Ministry of Health, Ankara Training and Education Hospital, Ankara, Turkey

The purpose of this study determine sleep pattern, sleep disorders and factors affecting on preschool-aged children.
Material-method The research was conducted on 999 patient 2-6 years presenting patient out-patient clinic. Parents were given a survey containing questions about the sociodemographic and sleep.

Results $30.9 \%$ of children were entering to bed in the hours 20.00 to 22.00 and $67.0 \%$ of children were entering to bed in the hours 22.00 to 00.00 . Sleeping and waking hours of children were found to be compatible with their parents ( $\mathrm{p}=0.001$ ). $50.2 \%$ of children with bedtime from 20.00 to 22.00 were fall asleep immediately and $22.6 \%$ of children with bedtime from 22.00 to 00.00 were fall asleep immediately $(p=0.001)$.We found that $62.9 \%$ of children snoring, $72.5 \%$ of children with mouth breathing, $38.7 \%$ of the children stopped breathing, $79.3 \%$ of the children were restless sleep, $80.2 \%$ of children saw a nightmare, $43.1 \%$ of the children gnashed teeth during the sleep. We found that snoring, mouth breathing were more than and sleeping hours were later for son children and nightmares were more frequent in girls $(p<0.05)$. We found that snoring, mouth breathing, restless sleep and frequent waking findings were more frequent in children with symptoms of attention deficit hyperactivity than in the other group.

Conclusions In the preschool-aged children, sleep disorders were common in. Sleep disorders were more frequent in children with hyperactivity symptoms. Primary care assessment of preschoolaged children should be questioned their sleep problems.

\section{DISCOVERED DEAD DURING SLEEP IN CAUSAL PATHWAY OF MORTALITY AMONG CHILDREN WITH CEREBRAL PALSY: CASE SERIES AND SYSTEMATIC REVIEW}

doi:10.1136/archdischild-2012-302724.1817

1,2L Holmes, 'A Karatas, 'D Kirk, 'J Connor, 'K Rogers, 'F Miller. 'Orthopedic Department, Nemours/A.I. Dupont Children Hospital, Wilmington; ${ }^{2}$ Biological Sciences, University of Delaware, Newark, DE, USA

Background and Aims To report thirteen cases of children with cerebral palsies (CP) discovered dead during sleep (DDDS) and to synthesize the research literature on CP survival.

Method We utilized case series to describe the common features among patients DDDS between 1993 and 2011. Using our medical records, we extracted data on demographics, treatment, and comorbidities. In addition using the appropriate search terms, we searched the Medline and other electronic data bases for articles published between 1966 and 2011. Further, we synthesized the literature and provided evidence on clinical conditions that could be associated with CP mortality in relation to DDDS, obstructive sleep apnea syndrome (OSAS) and sleep related breathing disorders (SRBD) management.

Results Between 1993 and 2011 there were 177 reported deaths, of which 13 occurred as a result of being DDDS at home. All the deceased patients had Gastrointestinal feeding tube, seizure, respiratory disorders, and were non-ambulatory. A greater proportion had scoliosis and hip dislocation surgeries. DDDS in our sample may be associated with these conditions; and OSAS/SRBD as evidenced in literature.

Conclusion Pulmonary problems and disorders were the most common co-morbidity, due probably to oxygen desaturation $(<70 \%)$, prolonged sleep apnea such OSAS and SRBD. Since there were no data on Polysomnography (PSG) and autopsy, it was difficult to account for specific sleep disorders that might have contributed to DDDS. We recommend a routine PSG and treatment of OSAS and SRBD, given their high prevalence among CP patients, especially those with disturbed nocturnal sleep and noisy breathing.

\section{SLEEP DISTURBANCES IN EPILEPTIC CHILDREN}

doi:10.1136/archdischild-2012-302724.1818 